\title{
Structural changes in solar corona during total solar eclipses
}

\author{
Marcel Bělík ${ }^{1}$, Eva Marková2 \\ and Miloslav Druckmüller ${ }^{3}$ \\ ${ }^{1}$ Observatory Úpice, 54232 Úpice, Czech Republic \\ email: belik@obsupice.cz \\ ${ }^{2}$ Observatory Úpice, 54232 Úpice, Czech Republic \\ email: markova@obsupice.cz \\ ${ }^{3}$ VUTBR Brno, Czech Republic \\ email: druckmuller@vutbr.cz
}

\begin{abstract}
Total solar eclipses observed on the long baseline allow to obtain the pictures of white-light solar corona with the long temporal distance. New mathematical methods of coronal picture processing allow visualization of very faint coronal structures and enable to compare their position in corona with very high accuracy. We can detect the moving of these faint structures by comparing of pictures obtained on the different places during the same total solar eclipse. Some techniques and results are described in this paper.
\end{abstract}

Keywords. Sun, corona, atmospheric motions

\section{Introduction}

Our team started try to find any faint structural changes in solar corona during the 1994 total solar eclipse. The 1995 and 1999 eclipses were further observed on long baseline. The first considerable results were obtained by our team in 1999 eclipse, when we had a chance to process the pictures obtained along very long part of totality belt. We analyzed decrease of brightness the structure of long helmet streamers and we found certain structural changes, which could be considered to represent either moving of coronal plasma or any types of coronal plasma waves. The typical speeds was found to be from 70 to $200 \mathrm{~km} / \mathrm{s}$ (Bělík et al., 2000). Unfortunately, the corona eclipse pictures processing procedures were not possible to show as faint as needed structures and consequently changes in their position in corona. It means the obtained results are not fully credible. Therefore we developed new numerical procedures (Druckmüllerová, 2005) allowed very precise align of individual frames to the final picture, as well as the procedures removing brightness decrease and enhancing structures of needed properties. Comparison of thus processed pictures obtained on the different observing places helps us to find as faint as possible structural changes in corona. These eclipse picture processing methods encourages us to start the MMV project.

\section{MMV project}

Fast computer processors, gigabyte sized memories and high resolution scanners together with newly developed mathematical methods make possible to create of corona images in the quality which was not possible to be reached years ago. In 2002 on the Brno University of Technology Miloslav Druckmüller started the project the aim of which is to develop new mathematical methods which make the processing of corona images more 


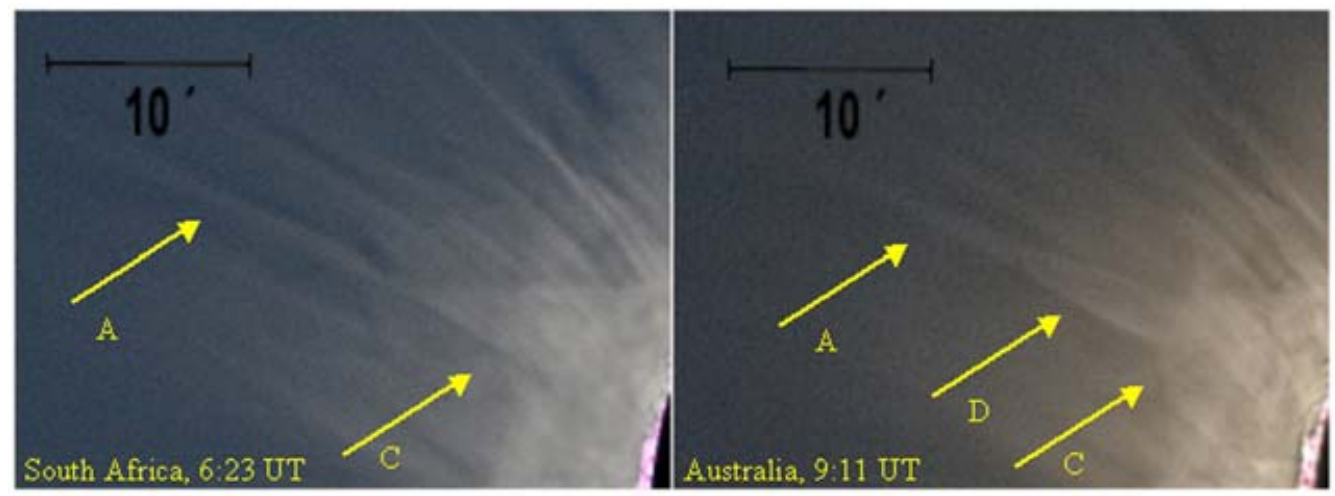

Figure 1. Composite images of 2002 eclipse in Africa and Australia. More significant changes are labeled by arrows.

effective, especially the highly precise registration, and to visualize coronal structures by means of adaptive filters inspired by human vision. The project is opened to any professionals or amateurs who have eclipse images of good quality and would like to participate on this project. More information and many processed eclipse images may be found on following project Web page: www.zam.fme.vutbr.cz/ druck/Eclipse/Index.htm.

\section{Coronal structure changes and conclusions}

The 2001, 2002 and 2005 total solar eclipses were observed at least on two different places and processed within MMV project (Marková et al., 2001, Dorst, 2005, Danielsen, 2005, Aniol, 2005, Rušin, 2005, Espenak, 2005). The comparison of them shows significant changes in structure of solar corona, which are clearly visible on the MMV project web pages. Only several types of relatively slow dynamic were studied yet. The speeds of these changes are typically from $4 \mathrm{~km} / \mathrm{s}$ to $20 \mathrm{~km} / \mathrm{s}$. The next eclipses are processed within MMV project at present time and they will be studied to get the next and more detailed view to the coronal plasma dynamics, especially the fast types.

\section{References}

Aniol, P.: 2005, private communication

Bělík, M., Marková, E., Brandejsová, E., Kučera, J., Kareš, J., Švanda, M.: 2000, Comparison of Coronal Structures 11.8.1999 on the Long Observation Base; Proc. of the 1st Solar and Space Weather Euroconfernce "The Solar Cycle and Terrestrial Climate", Santa Cruz de Tenerife 25-29 September 2000, ESA, SP-463 (December 2000), 587

Espenak, F.: 2005, private communication

Danielsen, A.: 2005, private communication

Dorst, F.: 2005, private communication

Druckmüllerová, H.: IAPPP Communications 99, March 2005, p. 1

Marková, E., Kotrč, P., Křivský, L., Bělík, M., Dušek, J. and Urban, J.: 2001, Total Solar Eclipse 2001 - Angola; Proc. 2nd Solar \& Space Weather Euroconference, "The Solar Cycle and Space Weather", Vico Equense, Italy, 24/29 September 2001 (ESA SP-447), Huguette Sawaya-Lacoste (Ed.), p. 245-248.

Rušin, V.: 2005, private communication 